\title{
Mobilidade Social na Idade Média: um breve estudo sobre os ministeriales na Alemanha
}

\author{
Social Mobility in the Middle Ages: a brief study on the ministeriales \\ in Germany
}

http://dx.doi.org/10.5007/2178-4582.2013v47n2p289

José Henrique Rollo

Universidade Estadual de Maringá, Maringá/PR, Brasil

\begin{abstract}
A imagem veiculada pelos manuais de história da sociedade europeia medieval como uma organização piramidal rígida usualmente negligencia alguns grupos sociais que experimentaram alguma forma de mobilidade social vertical. Um desses grupos foram os ministeriales ou dienstmänner, homens não-livres empregados pela Igreja e pela nobreza como burocratas e soldados. Embora tenham existido em diversos países, eles foram particularmente importantes na Alemanha dos séculos IX a XIII. Este artigo apresenta algumas de suas principais características como grupo social, analisa brevemente os padrões de mobilidade e expõe algumas das interpretações historiográficas a seu respeito.
\end{abstract}

Palavras-chave: Europa medieval - Alemanha - estratificação social - mobilidade social - ministeriales.
The image medieval European society conveyed by the history textbooks as a rigid pyramidal organization usually neglects some social groups who have experienced some form of vertical social mobility. One of such groups was the ministeriales or dienstmänner, composed by unfree men employed either by the Church and Nobility as bureaucrats and soldiers. Although they have existed in various countries, they were particularly important in Germany from IX to XIII centuries. This article presents some of its main features as a social group, briefly analyzes the patterns of mobility and exposes some of the historiographical interpretations on them.

Keywords: medieval Europe - Germany - social stratification - social mobility - ministeriales.

\section{Introdução}

Numa entrevista concedida a Véronique Sales, em 1996, o medievalista francês Dominique Barthélemy afirmou que a expressão sociedade feudal é uma mistura de concepção fundamentada e de mito $\square$ Segundo ele, a palavra e o modelo caminharam lentamente a partir do século XVII, mas atingiram sua maturidade por volta de 1830, com Guizot, que definiu os laços sociais da época feudal como laços de homem a homem (senhor e servo, senhor e vassalo) $\square$ Em sua opinião, esse modo de entender o que seria o fator sociológico essencial de um longo período da história da Europa Ocidental influenciou profundamente a historiografia e chegou, em boa medida intacto, aos dias que correm. No entanto, ele disse, a sociedade feudal é bem mais complexa do que isso, tecida de múltiplos laços de dependência, de solidariedade e de reciprocidade $\square$ Para ilustrar essa observação ele mencionou a diversidade e a mutabilidade das situações englobadas pelo termo servidão (servitus), um dos 
muitos que os medievais herdaram da Antiguidade Romana, sem que eles correspondessem, contudo, às mesmas realidades $\square \mathrm{E}$ lembrou, ainda, que o uso dessa palavra para indicar somente uma relação entre dois indivíduos obscureceu o fato de que muitos servos estavam atados por laços de dependência a organizações complexas, como as comunidades eclesiásticas, por exemplo (BARTHÉLEMY, 1996, p. 40).

Algo similar pode ser dito de outro grupo social que adicionou forte complexidade à sociedade feudal na Europa e escapou do modelo excessivamente simplificado que por muito tempo foi cultivado por diferentes correntes historiográficas, os ministeriales (ou ministerielles). Esta palavra também remete aos romanos, que designavam por minister alguém que desempenhava a função de servo ou assistente em casas, templos ou órgãos públicos (MARCHANT, 1904, p. 345). Contudo, embora tenha mantido sua acepção original, ela ganhou colorações diversas na Idade Média, quando foi usada para nomear indivíduos inicialmente destituídos de liberdade, que tinham em comum o servir como burocratas e militares a membros do clero, a reis e a nobres, mas que, ao longo do tempo, passaram por processos profundos de diferenciação entre si. De fato, a diversidade e a mutabilidade desse grupo social tornam-no muito difícil de definir, principalmente quando se busca uma caracterização sintética, e fazem-no matéria de muitos debates a respeito de seu escopo geográfico, de suas origens e de sua durabilidade.

No tocante às regiões, muitos historiadores contemporâneos usam o termo ministeriales apenas para denominar os indivíduos ligados a processos sóciopolíticos que ocorreram na Alemanha entre os séculos IX e XIII. ${ }^{1}$ Ecoando essa perspectiva, Paul Pixton (2001, p. 523) escreveu que eles formavam uma classe peculiar à Alemanha medieval $\square$, onde também eram chamados de dienstmänner, termo germânico que significa "homens a serviço". Na mesma direção, Christopher Gravett (1997, p. 17) observou, em seu livrinho sobre os militares durante a era dos Hohenstaufen, que um aspecto único do exército alemão era o emprego em largo número de um tipo especial de guerreiro, os cavaleiros não-livres ou ministeriales (Dienstleute) $\square$ E Barbara Rosenwein (2009, p. 277) bateu na mesma tecla: um grupo peculiar à Alemanha $\square$ Essas constantes observações sobre a localização dos ministeriales feitas nos livros de divulgação podem gerar a conclusão apressada de que eles somente existiram na Alemanha, o que não foi o caso, pois existiram servidores desse tipo na França, na Espanha, nos Países Baixos e na Inglaterra. Porém, nestes países eles nunca adquiriram a importância numérica e a força sociopolítica que tiveram no Sacro Império entre séculos X e XIII e, ademais, estiveram muito longe de possuir traços duradouros de homologia funcional com os alemães (BLOCKMANS; HOPPENBROUWERS, 2007, p. 144-145; 160).

\footnotetext{
${ }^{1}$ Uma observação geográfica: os limites do país que, desde o século XIX, chamamos de Alemanha não correspondem ao que foi conhecido na Idade Média Central como Germania ou, considerando especificamente o século XI, a parte leste da Francia. Naquela época, a área abrangida pelas casas aristocráticas avassaladas pelos reis sálicos estendia-se por parte do que é hoje a República Checa e o leste da Alemanha e da Áustria (apud BACKMAN, 2003, p. 181 n. 5; MUSTAFA, 2011, p. 17-18).
} 
Daí a concentração dos estudos nestes últimos. Seja como for, antes de nos voltarmos exclusivamente para a Alemanha, convém mencionar algo do que se passou em outros países com os homens de serviço e seus similares, bem como com outros grupos que eram designados pelas mesmas palavras usadas para nomeá-los.

Na França, desde ao menos o século VIII, os serviçais armados dos reis, aqueles que mantinham por via das armas a ordem nas cercanias do castelo e cobravam os impostos eram grifados nas fontes pelo termo sergents (DUBY, 1999 , p. 212-214). Mas, eles não eram funcionalmente tão diferentes dos ministeriaux que vicejaram nos séculos seguintes. Até o século XIII, esses termos foram empregados em larga medida para caracterizar determinados servidores das casas dinásticas, homens cujo estatuto jurídico era ambíguo, posto que eram nomeados por vocábulos que não mais corresponderiam à suas antigas acepções de origem romana ou alto-medieval (PARISSE, 1997). De todo modo, sabe-se que, no leste da França, até finais do século XIII, homens de origem servil foram utilizados como cavaleiros $\square$ e não somente como auxiliares a pé $\square$ nas tropas de alguns nobres (STRAYER, 1965, p. 25). Já na Espanha católica, pelo que disse, há muitos anos, Pedro Aguado Bleye, em seu compêndio de história medieval, Estado, Igreja e senhores particulares dispunham de dois tipos de servos, os personales ou ministeriales e os de la gleba (adscritos à terra). Os primeiros procediam de compra ou eram prisioneiros de guerra $\square$, o que sugere que eram efetivamente escravos (BLEYE, 1971, p. 510). Há, todavia, quem reserve o termo para os indivíduos (de origem livre, servil ou escrava) que desempenhavam ofícios (ministerium, mister, menester) prescritos nos foros (fueros) municipais (VALDEAVELLANO, 1960, p. 69-70). ${ }^{2}$

Nos Países Baixos, região diminuta em termos geográficos, mas de forte complexidade sociopolítica, a presença dos homens de serviço foi notável, entre os séculos X e XII. Notável ao ponto de, na Lotaríngia, os aristocratas de velha estirpe (os nobres de sangue) fazerem questão de que a origem escrava ou servil dos ministeriales ficasse expressa nos registros escritos. Essa atitude, porém, não se replicava em Flandres, uma área de pujantes atividades comerciais, na qual, ao longo do século XIII, o status dos administradores dos bens aristocráticos e eclesiásticos era suficientemente elevado para que, aos poucos, eles se misturassem com os patrícios e os proprietários rurais por meio de casamentos ou de parcerias em negócios (ARBLASTER, 2006, p. 62-66). Algo similar ocorreu, na mesma época, em grande parte da área que hoje é a Suíça. Lá a velha aristocracia fundiária também fazia questão de reivindicar o campo léxico da palavra livre para nomear seus membros, em clara contraposição aos descendentes de serviçais que galgaram a escadaria social ao lançarem mão de manobras parecidas para se mesclarem com segmentos

\footnotetext{
${ }^{2}$ Há registros do emprego de escravos nos serviços reais já em tempos visigodos. Um dos motivos que teriam levado à deposição de Vamba, que governou o Reino de Toledo entre 672 e 680, foi sua iniciativa de conceder cargos palacianos a não livres, o que desagradou profundamente os aristocratas. Estes temiam o poder que aqueles homens poderiam acumular e as conspirações que deles poderiam advir (MARTíN, 1993, p. 19).
} 
das elites tradicionais (PARISSE, 1997). Na Inglaterra, embora haja quem sustente que lá eles eram desconhecidos (SINGMAN, 1999, p. 8), para outros é perfeitamente cabível afirmar que eles tiveram um correlato nos servidores civis e militares que eram chamados de thegns ou nos denominados sergeants (BARRACLOUGH, 1976, p. 139-140).

No que tange às origens dos ministeriales, podemos correr o risco do excesso de simplificação e discriminar dois polos na historiografia. Um é o dos que advogam pela continuidade dessa forma de servidão entre a Antiguidade e a Idade Média. Eles ponderam que, não somente Roma, mas a Pérsia, a Grécia e outras sociedades complexas conheceram indivíduos que desempenhavam funções de guarda-costas, serviçais, cavalariços ou escrivães da mesma maneira que os ministeriales. Eles enfatizam os elementos funcionais ou organizacionais que teriam provocado a constituição em diferentes épocas e lugares de grupos sociais com esse perfil. Uma respeitável linhagem de pesquisadores das genealogias e dos tipos de Estados e dos modelos de administração pública envereda por esse caminho, sobretudo alocando-se no esteio de Max Weber e de alguns de seus herdeiros, como Shmuel Eisenstadt e Reinhard Bendix (apud CRONE, 2003, p. 67-68). O outro polo é composto pelos que buscam as particularidades medievais desse grupo tão difuso, evitando deliberadamente comparações de largo alcance e risco. A maioria dos historiadores que serão doravante mencionados enquadra-se neste segundo polo. Eles não se esquivam dos conceitos abrangentes, mas guardam cautela diante das generalizações ambiciosas que marcam o trabalho dos praticantes da Sociologia Histórica.

As páginas que se seguem não podem entrar a fundo em nenhuma das discussões acima referidas. Elas se limitam a fazer uma breve explanação didática, assinalando alguns aspectos das abordagens historiográficas e, principalmente, ressaltando sua complexidade. Mas é importante acentuar que, embora a ênfase recaia sobre um grupo social que vicejou predominantemente na Alemanha durante a assim-chamada Idade Média Central, ele é concebido em termos mais amplos como um mecanismo organizacional comum a várias sociedades antigas e medievais, a saber, o uso de indivíduos não-livres para desempenharem funções que deviam reforçar a autoridade dos governantes em uma ordem sócio-política sujeita a fortes pressões centrífugas (CRONE, 2003, p. 68). Noutras palavras, adota-se aqui, embora de maneira mitigada, a perspectiva associada ao primeiro polo interpretativo, o da Sociologia Histórica. Observe-se, então, que, a ideia de mecanismo organizacional orienta proposições interpretativas que, como juízos de síntese, são irredutíveis à fala dos atores. Ela contém um pressuposto comparativo destinado a aproximar o leitor contemporâneo de uma determinada experiência histórica que lhe é, em vários aspectos, imensamente distante, mas que pode adquirir racionalidade compreensível por meio de uma assertiva de cobertura ou um conceito.

Discutir uma passagem de Wim Blockmans e Peter Hoppenbrouwers (2007, p. 144-145) sobre o uso dos ministeriales pelos senhores banais pode ser um bom modo de aclarar a natureza de um mecanismo (ou recurso) or- 
ganizacional. Segundo eles, um modo de entender o processo de formação e expansão desse grupo social é articulá-lo com os projetos acalentados pelos senhores de acumulação/concentração de poder e autoridade. Isso teria caracterizado principados fortes, como o Ducado da Normandia, o Condado de Flandres e o principado-arcebispado de Hamburg-Bremen. Portanto, em principados mais fracos, ou seja, naqueles cujos senhores não estavam, por diversas razões, aptos a adquirir um patamar acentuado de independência diante dos monarcas e do alto-clero católico, não havia condições para mobilizar aquele recurso. O que importa notar é que, muito dificilmente encontraríamos documentos que contivessem falas explícitas a esse respeito. Todavia, isso não deve nos impedir de trabalharmos com a hipótese teórica de que certos componentes daquele segmento da elite dirigente da Europa Centro-Ocidental possuíam elevada clareza de objetivos e souberam agir de modo concertado para produzir instrumentos para atingi-los. ${ }^{3}$

Vistos ao longo de três séculos, os ministeriales assinalam aspectos da Europa Centro-Ocidental na Idade Média que, de um modo geral, são bastante simplificados pela bibliografia de vulgarização, entre eles, os mecanismos de mobilidade social. De fato, por mais que tantos historiadores tenham mostrado que, ao menos até meados do século XII, a famigerada pirâmide tripartite (os que rezam, os que guerreiam e os que labutam) tinha mais a ver com as idealizações legitimadoras da ordem do que com a distribuição hierárquica efetiva das pessoas na sociedade, ainda hoje essa é a representação dominante para descrever didaticamente a organização social da Europa medieval (apud BASCHET, 2006, p. 219-222). Isso acarreta a persistência de uma simplificação correlata: a ideia de uma impermeabilidade profunda e praticamente insuperável entre as camadas sociais. O resultado é a imagem quase imóvel de uma sociedade estamental controlada pelo alto-clero e pela alta-nobreza, elites que se reproduziam por meio de matrimônios, carreiras eclesiásticas e relações de vassalagem, mantendo umas poucas famílias aristocráticas permanentemente no topo da pirâmide (apud BARTHÉLEMY, 2000; BACKMAN, 2003, p. 176-181). O estudo dos ministeriales permite que se questione essas simplificações.

\section{Observações sobre as noções de grupo e mobilidade social}

De acordo com Tilmann Lohse (1990, p. 17), um olhar sobre o desenvolvimento dos ministerielles e da cavalaria pode nos dizer bastante acerca da mobilidade social dos estratos mais altos da sociedade medieval $\square$ Embora inicialmente eles fossem recrutados entre os homens não-livres, não raro de origem camponesa, para cumprirem tarefas administrativas e militares nas propriedades da Igreja e dos nobres, muitos conseguiram adquirir grandes for-

\footnotetext{
${ }^{3}$ A partir de uma hipótese difusionista, é possível sugerir que os aristocratas se espelharam em experiências bem sucedidas noutras regiões. O emprego de escravos do governante em funções de serviços administrativos e, ocasionalmente, militares, ocorreu no Califado de Córdoba, na Espanha, e nos Emirados dos Tulunidas e dos Ikhshidids, no Egito, entre 869 e 935 (LINDSAY, 2005, p. 57-79). Essa não é, porém, a via de análise perseguida nestas páginas.
} 
tunas, terras e servos, constituindo a longo prazo segmentos aristocráticos que disputaram poder e prestígio com as famílias da nobreza tradicional. Noutras palavras, o trajeto de muitos ministeriales sugere que, entre os séculos $\mathrm{X}$ e XIII, nas áreas que hoje correspondem à Alemanha, operaram vetores de mobilidade vertical que desencadearam importantes processos de diferenciação social e, também, que o mecanismo organizacional que os originou foi bastante eficiente, ao menos por um certo tempo. Diante disso, é preciso dar uma palavra sobre as noções de grupo e mobilidade social. É importante fazer isso porque, toda vez que se usa termos extraídos do vocabulário sociológico para analisar fenômenos ocorridos em época ou lugares muito distantes das sociedades modernas, são automaticamente desencadeadas diversas questões polêmicas a respeito do âmbito de validade temporal dessas noções e das relações entre as unidades terminológicas e os objetos que elas pretendem descrever.

Para começar, o termo grupo social. Aparentemente, ele é bem fácil de ser definido. Por exemplo: um conjunto de indivíduos que compartilham determinados atributos que um observador considera suficientemente distintos e significativos para conferir-lhes uma dada identidade. Tal definição não pressupõe que os indivíduos englobados se conheçam ou mesmo que tenham alguma consciência dos traços que os diferenciam dos demais grupos. Desta perspectiva, quem define o valor dos atributos e demarca a extensão do coletivo é o sujeito que manuseia o vocabulário descritivo. No entanto, é preciso não esquecer as dimensões subjetivas ou internas na demarcação de um grupo (HANSEN; RAPLEY, 2006; HOLY, 2003). Neste sentido, Mario Aldo Toscano (2006, p. 199-200) observou que, as teorias sociológicas não podem fazer menos do que sublinhar, ainda que seus desenvolvimentos sejam diferenciados, este sentido de pertencimento chamado solidariedade, esprit de corps, vontade comum etc. como traço fundamental do grupo $\square$ Por esta mesma via, os autores de um dicionário de sociologia assinalaram que o termo grupo denota um número de indivíduos, definido por critérios formais ou informais de pertencimento, que tem algum senso compartido de identidade e é delimitado por padrões relativamente estáveis de interação social $\square$. Eles diferenciam grupo de um simples agregado estabelecido por atores externos, como é o caso dos observadores sociológicos, sugerindo que os membros do primeiro têm alguma noção de que são partes dele (BRUCE ; YEARLEY, 2006, p. 128).

Embora Tilmann Lohse a tenha evocado para descrever processos ocorridos com os ministeriales, a expressão mobilidade social, que designa a mudança de posição ou status de um indivíduo ou de um grupo de pessoas no interior de uma sociedade, sofre, igualmente, restrições ao seu uso para épocas passadas. Avaliando o fenômeno a partir das pautas de organização social e de atribuição de status que caracterizariam o Mundo Contemporâneo, a saber, a valorização do indivíduo e o relativo repúdio aos padrões tradicionais de legitimação da ascensão a estratos mais endinheirados e prestigiados, como a proveniência e o patrimônio familiar, uma socióloga italiana afirmou que "a mobilidade constitui nas suas diversas formas o eixo que sustenta a mudança e a dinâmica social $\square$ (CURCIO, 2005, p. 94). Noutras palavras, ocorrên- 
cias de mobilidade seriam traços intrínsecos às sociedades capitalistas, nas quais mudanças dos mais diversos tipos são constantes, diferentemente do que acontecia nas sociedades pré-modernas, quando eram raras, tão raras que, para alguns, não parece adequado lançar mão desse conceito para falar de fenômenos excepcionais (CRONE, 2003, p. 172). Contudo, por mais fortes que sejam esses senões, tem cabimento empregar a expressão mobilidade social para designar processos que aconteceram, apesar dos poderosos mecanismos de enrijecimento das camadas sociais característicos das sociedades de tipo feudal, em uma época bem definida, os séculos X a XIII na Alemanha.

Essa posição teórica estriba em constatações empíricas (que serão explicadas mais a frente) como as de Norman Cantor, para quem, naquele período de avanços tecnológicos no setor agrícola, crescimento urbano e expansão das atividades mercantis, a oportunidade para os camponeses mais jovens e mais pobres eram similarmente mais promissoras e maiores no décimo século do que antes ou depois, por, no mínimo, outros quatrocentos anos $\square$ (CANTOR, 1994, p. 229). Segundo ele, na Alemanha, mais exatamente, "os filhos mais robustos dos camponeses tiveram um tipo especial de oportunidade para melhorarem sua condição: alguns se tornaram ministeriales régios e terminaram como capitães de castelos reais $\square$ (Ibid., p. 229-230). Portanto, não é o caso de defender a ideia de que ao longo de toda a Idade Média existiram possibilidades permanentes de mobilidade social para um número grande de indivíduos, mas de realçar o fato de que a historiografia chamou a atenção para as peculiaridades da Alemanha no período assinalado. Teriam os ministeriales adotado medidas táticas conscientes para aproveitarem as oportunidades de ascensão que se apresentaram? Ou os percursos dos que subiram a escada social foram efeitos inesperados de uma intenção completamente diversa, a construção de mecanismos organizacionais destinados a reforçar a autoridade dos monarcas e a eficácia gerencial das propriedades eclesiásticas e aristocráticas?

Essa ligeira discussão de noções sociológicas remete à hipótese que se quer discutir. Ela é basicamente a seguinte: alguns indivíduos que compuseram o grupo dos ministeriales perceberam que se conseguissem garantir direitos hereditários para o usufruto dos bens que recebiam por seus serviços, suas famílias ascenderiam socialmente a largo prazo. Elas continuariam não-livres, desprovidas de direitos similares aos dos cavaleiros e clérigos livres. E continuariam sendo vistas como destituídas de passado honroso, algo fundamental para o ingresso na aristocracia tradicional. Mas poderiam acumular fortunas e capitalizar prestígio. Aqueles indivíduos, em particular os mais opulentos, devem ter agido, também, para que, mediante matrimônios entre seus filhos e entre estes e os membros da velha nobreza, fossem abertos canais de ingresso nos meios aristocráticos. Algo parecido aconteceu nas relações com o patriciado urbano. Sabe-se de muitos ministeriales que enriqueceram praticando usura e/ou se associando a empreendimentos mercantis. Alguns se tornaram autoridades municipais, encarregadas da administração, do policiamento, da organização das festas e outras celebrações (BARRACLOUGH, 1976, p. 139140, 162). Mais significativamente, ainda, membros de famílias fundadas por 
ministeriales chegaram a ocupar cargos eclesiásticos e militares poderosos. Nestes casos, eles praticamente não se diferenciavam dos nobres de velha estirpe, embora fossem, com frequência, mal vistos e combatidos por estes (GROTEN, 1990, p. 72; CORRAO, 2003, p. 352).

As discussões de ordem terminológica feitas acima e os dados empíricos colhidos entre os historiadores que as sustentam partem de um fator limitador dado pelo modo predominante de se enquadrar os homens de serviço alemães medievais na historiografia de divulgação: assume-se que o fenômeno é relevante no espaço sócio-político de fala predominantemente teutônica que constituía a herança mais ao leste da Francia dos sucessores de Carlos Magno. Contudo, a presença de ministeriales nas regiões configuradas pelo Drang nach Osten, nos séculos XII e XIII, não deve ser negligenciada. Esse movimento $\square$ ora acelerado, ora lento, mas persistente $\square$ foi, em boa medida, um processo de expansão colonial germânica sobre o Mundo Eslavo (BARRACLOUGH, 1976, p. 118-119). Suas razões são motivos de fortes debates entre os historiadores, entre outras coisas porque ele foi evocado muitas vezes, desde o século XIX, para confirmar certas ideias a respeito de um possível caráter nacional alemão caracterizado pela vocação expansionista e, também, para ilustrar uma perspectiva de explicação histórica baseada no confronto entre raças ou nações, no caso, os germânicos versus os eslavos (BURLEIGH, 1985). Cabe notar que, entre os séculos XII e XIII, a área coberta por populações de fala germânica praticamente dobrou (DETWILER, 1999, p. 54).

Para o que interessa neste momento, deve-se apenas reter que as terras a leste atraíam os camponeses submetidos a tributos escorchantes e à crescente fragmentação da propriedade familiar, os cavaleiros em busca de construir seu próprio patrimônio feudal e, evidentemente, os grandes senhores guerreiros. Também representavam oportunidades de negócios para os mercadores e os artesãos, além de uma frente de ação pastoral para os sacerdotes. Noutras palavras, o Drang nach Osten ensejou vetores de mobilidade social que se beneficiavam da maior disponibilidade de recursos naturais (BURKS, 1961, p. 2-3). Muitos camponeses se mudaram com seus parentes e pertences para as regiões que hoje correspondem ao leste da Alemanha, à Áustria e à Boêmia e lá foram instalados por locatores, empreendedores de colonização que se tornaram a coluna vertebral de uma nova aristocracia de fronteira $\square$ (DETWILER, 1999, p. 54). Outros seguiram em frente, instalando-se no que agora são a Polônia e a Hungria, empregados por senhores de terras que precisavam de mão de obra para a drenagem de áreas pantanosas, a derrubada de matas e o plantio. Algumas dessas populações foram, mais tarde, assoladas pelas guerras entre os cavaleiros teutônicos e os nobres poloneses, estes aliados de aristocratas prussianos (BURKS, 1961, p. 10-15). Os processos de colonização desencadeados pelos alemães em regiões a leste beneficiaram amplamente os ministeriales. Muitos conseguiram acumular terras e fortunas, bem como prestígio e poder sobre pequenas cidades. Eles se tornaram contrapesos aos príncipes territoriais que, no esteio do declínio dos Staufen, esperavam governar sem opositores $\square($ ROSENWEIN, 2009, p. 277). Ao que parece, observou Detwiler, 
em que pesassem o vigor da expansão colonial e a violência das guerras, não chegaram a se formar sentimentos anti-germânicos entre os eslavos daquela região antes de bem entrada a Modernidade (DETWILER, 1999, p. 54-55).

\section{Processos de formação e diferenciação dos ministeriales: algumas expli- cações}

Não se sabe muito bem quando foi que os bispos e, depois deles, os aristocratas do Sacro Império passaram a recrutar homens não-livres para empregá-los nos serviços administrativos e militares. A maioria dos historiadores afirma que isso aconteceu principalmente a partir do século X (com umas poucas incidências no século IX) por iniciativa de autoridades eclesiásticas, que desconfiavam da lealdade e do zelo de independência dos cavaleiros. Elas preferiam confiar as tarefas de organização e gerenciamento dos bens a indivíduos advindos das famílias servis. Teriam, assim, conservado a palavra latina que nomeava quem executava várias dessas atividades e, ao mesmo tempo, indicava sua condição jurídica de não-livre, de dependente. Também não é muito claro o modo como isso foi feito e a amplitude da extração social dos indivíduos transformados em ministeriales. Alguns autores asseveram que eles provinham dos camponeses pobres e dos extratos mais baixos dos cavaleiros (PIXTON, 2001, p. 523; CANTOR, 1994, p. 221-222). Outros procuram diferenciar as camadas sociais em relação à condição de não liberdade: os camponeses e muitos indivíduos (e famílias) da baixa nobreza não eram livres, mas experimentavam essa situação de modos bem diversos. Eles explicam a formação dos ministeriales a partir desses segmentos da baixa nobreza (fundamentalmente cavaleiros empobrecidos avassalados por um senhor mais forte e prestigiado), observando que, embora também tenha ocorrido recrutamento entre os camponeses, esse foi bem menos significativo (DETWILER, 1999, p. 30-31; GRAVETT, 1997, p. 17-18). E um professor de história norte-americano do começo do século XX, chegou a falar em middle class para designar a procedência desses homens (BROWN, 1932, p. 180).

$\mathrm{Na}$ documentação do período $\square$ que, em linhas gerais, mantém numerosas palavras de origem romana $\square$ aparecem vários substantivos que nomeiam a diversidade das tarefas associadas ao termo ministeriales. Eles foram recolhidos em muitas obras da primeira metade do século XIX, época em que os historiadores estavam obcecados com as descrições taxionômicas. Assim, em 1842, Philippe le Bas, conferencista na École Normale de Paris, explicou que, no começo da Idade Média, encontravam-se na Europa, duas grande classes de escravos $\square$, os que eram ligados à terra, geralmente chamados de coloni, e os que eram vinculados aos ofícios domésticos, designados como ministeriales. Entre estes havia vários tipos: $\square$ major-domus, ou simplesmente major, que comandava os outros escravos ; o Infestor, aquele que põe os pratos sobre a mesa $\square$ o Sceantio, mais tarde chamado de Buticularius, cujo papel era servir a bebida aos senhores; o Marescalcus, encarregado de tomar conta dos cavalos de luxo $;$; o Strator, que era o escudeiro, e o Senes- 
chleus, inspetor do aposento do príncipe ou do conde $\square$ (LE BAS, 1842, p. 449-450). Bem ajustado ao gosto por tipologias, ele optou por decompor o que as fontes descreviam como atribuições dos ministeriales, mas evitou datas e lugares precisos. Não ficamos sabendo quando eles surgiram e quando desapareceram. Tampouco somos informados de sua ocorrência no espaço, ainda que fique subentendida sua presença no mundo dos francos, que incluía partes da atual Alemanha.

Contudo, essas questões polêmicas não impediram até agora que haja uma sorte de relato histórico mais ou menos normalizado a respeito desse grupo muito peculiar de homens de serviço. No que se segue, dá-se vazão a esse relato padronizado, captado em diferentes autores, mesmo correndo o perigo de algumas repetições e simplificações. Pois bem. As primeiras menções aos ministeriales como grupo social na Idade Média alemã têm a ver com sua atividade como administradores civis de bens eclesiásticos. Segundo Barraclough, que aponta a insuficiência das fontes para conclusões muito precisas, "os ministeriales foram empregados pela primeira vez provavelmente por bispos em propriedades episcopais e os sálicos devem ter percebido as vantagens $\square$ (BARRACLOUGH, 1976, p. 162). No entanto, os registros a esse respeito são muito raros. O que se sabe é que Conrad II foi o primeiro rei alemão a favorecê-los como uma classe e a organizá-los em uma espécie de staff administrativo $\square$ (BARRACLOUGH, 1976, p. 162). O historiador britânico observou que os homens de serviço se constituíram em uma nova classe de administradores $\square$, que $\square$ rapidamente cresceram em importância, apartaram-se do corpo principal de servos arrendatários ordinários e tornaram-se os principais agentes da política real $\square$ (BARRACLOUGH, 1976, p. 162).

Essa também é a perspectiva de Tilmann Lohse. Sua análise dos dienstmänner aloca-os nos quadros da nobreza alemã, acentuando que esta era fortemente diferenciada internamente. Embora formassem a aristocracia e controlassem $\square$ como um grupo social $\square$ os altos e médios cargos eclesiásticos, bem como o acesso aos conventos, as famílias da nobreza nem sempre eram muito ricas e nem sempre detinham larga soma de poder. Ademais, seu status legal era bastante estratificado. Nesta direção, ele distingue quatro camadas de nobres: o rei, os príncipes, a nobreza que não era composta por príncipes e os ministeriales, que formavam seu nível mais baixo (LOHSE, 1990, p. 16). Ser nobre era, a princípio, ser um guerreiro a cavalo, e isso era caro. Na Alemanha dos séculos X e XI, um cavalo valia de cinco a dez bois e uma armadura muito mais. Ir a uma batalha significava levar mais do que o cavalo que transportava o guerreiro. Era preciso ter um outro que, descansado, fosse usado na refrega. E mais um para transportar mantimentos e equipamentos. Ser cavaleiro era, portanto, dispor de posses. Ter ambições de erguer-se à alta nobreza e fundar uma dinastia exigia formar uma tropa e ter muitos outros auxiliares (FLORI, 1998). O recrutamento desses indivíduos era feito entre os homens nascidos livres (edelfrie) e, crescentemente, fora dos círculos aristocráticos, entre os homens não-livres subordinados. Desse último grupo vieram os que formaram a $\sqsubset$ classe dos ministerielles $\square$ (LOHSE, 1990, p. 17). 
Note-se que, ao contrário de uma corrente ampla da historiografia, esse historiador germânico não dá uma ênfase muito pronunciada ao papel dos sacerdotes nas origens dos homens de serviço. Sua preocupação maior é analisar como esses indivíduos se tornaram membros da nobreza. Noutras palavras, chamar a atenção para a presença na Idade Média Central de um mecanismo de mobilidade social. Sua abordagem é, em síntese, a que se segue. No passado, os nobres puderam recrutar seus soldados entre os camponeses que lhes deviam serviços e obrigações. Todavia, conforme cresceram os confrontos no seio de sua classe, eles foram forçados a manter tropas permanentes. $\mathrm{O}$ aumento das guerras inviabilizou o emprego de camponeses. As terras ficavam abandonadas, os cultivos eram paralisados, muitas coisas eram destruídas e as famílias mais fracas eram reduzidas à servidão. Naquele contexto, uns poucos indivíduos das camadas populares conseguiram entrar para tropas de cavaleiros e, tornando-se vassalos, chegar aos níveis mais baixos da nobreza (LOHSE, 1990, p. 17). Outros fatores operaram na formação dos dienstmänner. A partir de meados do século X, a Alemanha entrou em uma fase de notável crescimento e diferenciação de atividades no seio da economia, bem como de aumento da população. Nessa época, deu-se a consolidação das propriedades territoriais da alta nobreza, o que demandava novas formas de organização dos processos administrativos. No entanto, não havia muita gente livre disponível para essas tarefas. Era preciso empregar servos. Os membros da nova classe de ascensores sociais, os ministerielles, necessitavam ser bem providos com bens materiais para que estivessem aptos a atender aos serviços cavalheirescos. [Eles] necessitavam de propriedade da terra e de camponeses subordina$\operatorname{dos} \square$ (LOHSE, 1990, p. 18).

No século XI, conforme conseguiram manter suas propriedades e legá-las aos herdeiros, eles subiram para a baixa nobreza. Ademais do serviço militar, eram responsáveis pela economia das propriedades senhoriais. Eles supervisionavam os trabalhadores rurais, os artesãos (moleiros, padeiros, ferreiros, pedreiros etc.) e os mercadores não-livres. Também cuidavam da construção e da manutenção dos castelos. Na opinião de Tilmann Lohse, essa posição entre as classes mais baixas e os estratos superiores foi o começo de muitas carreiras. Foi também o início de uma nova classe aristocrática $\square$ (LOHSE, 1990, p. 18). De fato, os ministeriales assumiram funções e tarefas que cabiam usualmente aos príncipes. Muitos se tornaram parte da nobreza territorial. Muitos ascenderam até a alta aristocracia. E puderam aproveitar o crescimento das cidades, onde se associaram aos comerciantes. Esse enriquecimento, enfim, permitiu que muito superassem a condição de não-livres. Segundo ele, sabe-se de casos de nobres livres que voluntariamente viraram servidores, o que sugere que havia vantagens em ser ministerialis $\square(\mathrm{LOH}-$ SE, 1990, p. 18). Porém, é certo que existiam profundas diferenças no interior do grupo dos homens de serviço e elas tinham a ver, basicamente, com as diferenças entre os senhores. Seja como for, a alta nobreza era inspiradora de comportamentos que, em vários aspectos, unificavam o grupo. Os bemsucedidos eram modelos a serem imitados. Forjou-se até uma espécie de sub- 
cultura cortesã, embora bem limitada e rudimentar. No século XIII, época em que muitas famílias da nobreza tradicional desapareceram, os ministeriales chegaram finalmente aos altos estratos aristocráticos e, por volta de 1300, compunham cerca de $80 \%$ dos nobres. Tudo isso the possibilita concluir que, durante a Alta Idade Média na Alemanha, a nobreza ainda não começara a evitar contatos com as classes mais baixas como fez na Idade Média tardia, quando os ministeriales pertenceram à nobreza $\square$ (LOHSE, 1990, p. 18).

Alguns historiadores exploram bastante a linha de abordagem centrada no desempenho de funções administrativas. Elas teriam permitido a formação de quadros burocráticos capazes de coordenar operações de melhoramento técnico nas propriedades, de aperfeiçoamento dos mecanismos de captação de tributos, de armazenamento de informações, de gerenciamento dos bens móveis e imóveis do alto-clero e das famílias da alta-nobreza, principalmente as dos monarcas (TURK, 1999, p. 33-46). Esse novo patamar de eficácia organizacional foi acompanhado por um crescente prestígio dos ministeriales das casas reais. Os que eram empregados pelas igrejas também pareciam gozar de grande estima. Eles realizavam o trabalho diário de administração e provimento dos bens, mas também eram encarregados de cuidar dos peregrinos e de outros serviços bastante valorizados. Ademais, iam à guerra por seus bispos. Para alguns, as recompensas em termos de prestígio e mobilidade social ascendente não demoraram. A partir do século XI, podiam-se achar nas cidades alemãs dientsmänner que eram tão opulentos, influentes e prestigiados quanto os mercadores que negociavam a longa distância. Com o passar do tempo, muitos ministeriales tornaram-se membros dos conselhos das cidades. Eles não tinham status de homens livres. Tampouco eram protegidos e beneficiados pelas leis que asseguravam privilégios aos burgueses (citadinos livres). Porém, como representantes dos bispos, conseguiam poder suficiente para manter seus esquemas de clientela, angariar favores e conseguir que seus filhos e filhas subissem um bom número de degraus na escada social (GROTEN, 1990, p. 72).

Preservaram-se alguns nomes de ministeriales das casas monárquicas que se beneficiaram da hereditariedade da condição e, ao longo do século XII, conseguiram não somente obter o status de homens livres como galgaram posições na aristocracia e no alto-clero. Geoffrey Barraclough lembrou de Werner, chefe-servidor de Conrad II, e de Benno. O primeiro foi $\square$ mais antigo ministro secular na história da Alemanha $\square$, a quem cabia supervisionar as propriedades reais como $\square$ uma espécie de controlador geral $\square \mathrm{O}$ segundo, que serviu a Heinrich III, foi mordomo do palácio imperial em Goslar e administrador-chefe das terras da coroa. Em 1054, o monarca nomeou-o bispo de Osnabrück, uma nomeação que assinala a primeira brecha na até então essencialmente aristocrática constituição da igreja alemã $\square$ (BARRACLOUGH, 1976, p. 162). Dois outros ministeriales imensamente bem sucedidos também devem ser citados. Um deles foi Werner II de Bolander, que serviu à Friedrich (Barba Ruiva) e a mais 45 outros senhores. Ele acumulou feudos, chegou a ter 17 castelos e a comandar 1100 cavaleiros. Um de seus descendentes tor- 
nou-se arcebispo de Mainz em meados do século XIII. Outro foi Markward de Anweiller. Emancipado por Heinrich IV, que o nomeou Duque de Ravena e Romagna, ele recebeu a regência da Sicília, em 1197, pouco antes da morte do rei, e coube-lhe a tarefa de cuidar do jovem Friedrich (PIXTON, 2001, p. 524).

Essas carreiras notáveis não devem, contudo, escamotear o fato de que a grande maioria das famílias de ministeriales jamais saiu das camadas mais baixas e permaneceu atada aos laços servis com seus senhores. E não devem, do mesmo modo, obscurecer a percepção do processo de mobilidade vertical como um fenômeno coletivo de implicações não apenas sociais (no sentido mais estrito da palavra), mas também políticas (BLOCKMANS; HOPPENBROUWERS, 2007, p. 144-145). Ao final do reinado da dinastia dos Hohenstaufen, os homens de serviço estavam se organizando em uma ordem (estado) de cavaleiros imperiais (Reichritterschaft). Durante o século XIII, sacerdotes originários daquele grupo confrontaram os membros das hierarquias clericais que pertenciam a famílias da velha nobreza. Isso ocorreu em várias dioceses. Também houve casamentos com mulheres nobres. Ministeriales acabaram se tornando o patriciado em muitas cidades. Ademais, Conrad de Daun (ou de Tanne) virou bispo de Speyer, em 1233, e Conrad de Durkheim tornou-se bispo de Worms, em 1247 (PIXTON, 2001, p. 524).

Há uma outra linha de enfoque dos homens de serviço que se notabiliza por dar forte ênfase aos elementos militares. Ela não se opõe de todo à que foi exposta até agora, porém, suas premissas e suas conclusões são um tanto diferentes. Para resumi-la, veja-se o caso (bastante representativo, apesar de tantas décadas terem se passado) de Sydney Brown. Em 1932, animado por uma postura historiográfica segundo a qual a precisão factual deveria alimentar uma perspectiva analítica centrada nos indivíduos empreendedores, ele explicou as origens dos homens de serviço militares pela combinação de fatores globais com a perspicácia de um governante, Heinrich I, o Duque da Saxônia, eleito rei em 919. Ao assumir o trono, Heinrich passou a liderar os cavaleiros que lhe eram vassalos no combate aos magiares (húngaros) que estavam atacando e pilhando as terras dos germânicos. Em 924, um dos comandantes invasores foi capturado e seu resgate ficou condicionado a uma trégua de nove anos que, dada a fragmentação dos principados, valeu somente para a Saxônia e a Turíngia. Os ataques a cavalo dos húngaros teriam mostrado aos chefes militares alemães os limites de sua capacidade. Eles não poderiam contar apenas com uma infantaria composta por homens livres ocasionalmente mobilizados e precisavam, portanto, organizar uma cavalaria, a única força capaz de se opor a outra cavalaria. "Diante dessa dificuldade, Heinrich voltou-se para seus ministeriales (homens empregados em serviços pessoais ou oficiais por Heinrich como duque e como rei), e a partir deles formou o núcleo de seu novo exército (BROWN, 1932, p. 137). A retomada dos confrontos com os húngaros, em 933, foi feita com esse novo quadro de cavaleiros. Daí em diante, vários notáveis da alta nobreza adotaram as mesmas medidas militares e os governantes que lhe sucederam buscaram reforçar o grupo dos ministeriales reais. 
A princípio, a explicação do historiador norte-americano desconsiderava os confrontos no interior da aristocracia e do alto-clero, carregando nos fatores de causalidade externa. Os alemães, mais propriamente, os saxões e os turíngios, teriam se beneficiado coletivamente da criação das tropas de ministeriales, posto que puderam reagir de modo mais eficiente às ameaças dos invasores. Todavia, mais tarde, ao mencionar o reinado de Conrad, na primeira metade do século XI, Brown lista as medidas que ele tomou para fortalecer sua autoridade. Ele procurou se apoiar na baixa nobreza, usando-a como contrapeso ao poder dos magnatas, que guardavam o valor de sua condição de cavaleiros livres e não estavam dispostos a votar fidelidade absoluta ao monarca. Também ampliou o uso de clérigos como administradores e conselheiros e lançou mão dos ministeriales, que se transformaram em uma nova classe hereditária $\square$ (BROWN, 1932, p. 158). Nos governos de Heinrich IV e Heinrich V expandiu-se o número de homens a serviço dos monarcas, recrutados na classe média (middle class) e na baixa nobreza. Tamanha se tornou a importância dos ministeriales que, segundo reza uma tradição, Friedrich (Barba Ruiva) chegou a dizer o seguinte para um deles: Eu daria duas rainhas por outro como você $\square$ (apud BROWN, 1932, p. 188).

\section{Conclusões}

Por grande parte das áreas rurais da Europa Ocidental, os séculos XII e XIII testemunharam uma forte diminuição da viscosidade (que nunca foi muito alta), dos canais de mobilidade social e a acentuação da fragmentação do poder político, consolidando-se (ainda que não por muitos séculos) os poderes feudais tipificados na autoridade do grande castelo (BASCHET, 2006, p. 139-217). A Alemanha viu tanto a nobreza de base rural quanto o patriciado urbano se enrijecerem e as distâncias entre os estratos sociais superiores e inferiores se aprofundaram. Também viu que, trezentos anos depois de serem desencadeados, os intentos de centralização política dos Sálicos e, depois, dos Hohenstaufen, malograram. Esses processos não foram peculiares à terra dos germânicos, mas lá eles adquiriram significados particulares que instigam a reflexão conceitual, uma vez que, segundo a terminologia empregada neste estudo, os mecanismos organizacionais que possibilitaram a formação e a diferenciação dos ministeriales deixaram progressivamente de funcionar. Noutras palavras, um veículo de mobilidade social, que não foi concebido com essa intenção manifesta, foi bloqueado. A expansão daquele grupo resultou, antes de mais nada, dos projetos de concentração de poder e autoridade dos monarcas germânicos. ${ }^{4}$

\footnotetext{
${ }^{4}$ Embora não seja nada fácil (e essa não foi a proposta desse breve estudo) estabelecer uma comprovação documental dessa ideia, nada nos obsta aventar a possibilidade de que o funcionamento efetivo daquele mecanismo dependia, em alguma medida, dos interesses dos próprios homens de serviço. Vários daqueles indivíduos conseguiram percorrer os caminhos que permitiram que eles e seus familiares ascendessem socialmente. Tornaram-se membros livres da aristocracia, embora continuassem a carregar o fardo simbólico da origem plebeia. A maioria, contudo, não teve esse mesmo desempenho e permaneceu não-livre, isto é, sem capacidade para tomar diversas decisões altamente codificadas socialmente, como a escolha conjugal ou o direito de se deslocar para longe das terras senhoriais (ROSENWEIN, 2009, p. 277).
} 
Encerremos, então, estas breves digressões apontando (mas apenas apontando) uma questão teórico-metodológica que emerge do que foi escrito acima. Ela tem a ver com o alcance da ideia de mecanismos/recursos organizacionais, em particular um tipo específico, os homens de serviço extraídos de grupos em condição escrava ou servil. Esse tipo de proposição interpretativa é muito útil para gerar explicações funcionalistas para fenômenos bem delimitados no tempo e no espaço e bastante adequado para o desenho de estudos históricos comparativos. Assim, aplicado como hipótese de enquadramento, ele parece bem-sucedido para interpretar o que ocorreu na Alemanha, sobretudo entre os séculos X e XI e ajuda a compreender, por exemplo, aspectos do Império Otomano, entre meados do século XV e meados do século XVII, quando o emprego de escravos na administração e nas armas foi de amplo êxito como instrumento de centralização do Estado e de contenção das forças sociopolíticas centrífugas (PEDANI, 2006, p. 41-72). Todavia, não se deve esperar demais dessas formulações sintéticas. E não se lhes deve dar o condão de substituírem a investigação histórica convencional.

\section{Referências}

ARBLASTER, Paul. A History of the Low Countries.Hampshire. New York: Palgrave Macmillan, 2006.

BACKMAN, Clifford R. The Worlds of Medieval Europe. New York: Oxford University Press, 2003.

BARRACLOUGH, Geoffrey. The Crucible of Europe: The Ninth and Tenth Centuries in European History. Berkeley/Los Angeles: University of California Press, 1976.

BARTHÉLEMY, Dominique. La féodalité a-t-elle existé? LHistoire, [S.1.], n. 205, p. 40-43, Décembre 1996.



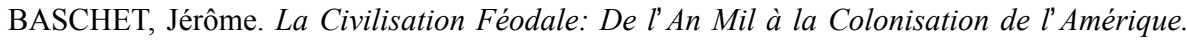
Troisième édition. Paris: Flammarion, 2006.

BLEYE, P. Aguado. Manual de Historia de España. 11 a Edición. Madrid: Espasa-Calpe, , 1971. Tomo I.

BLOCKMANS, Wim; HOPPENBROUWERS, Peter. Introduction to Medieval Europe, 3001500. New York/London: Routledge, 2007.

BROWN, Sydney M. Medieval Europe. New York: Harcourt, Brace and Co., 1932.

BRUCE, Steve; YEARLEY, Steven. The Sage Dictionary of Sociology. London: Sage, 2006.

BURKS, R. V. Some Elements of East European History. Washington: American Historical Association, 1961. 
ROLLO, José H. Mobilidade Social na Idade Média: um breve estudo sobre os ministeriales na...

BURLEIGH, Michael. The German knights: making of a modern myth. History Today, p. 2429, June 1985.

CANTOR, Norman F. The Civilization of the Middle Ages. New York: HarperPerenial, 1994.

CORRAO, Pietro. Regni e principati feudali. In: ARTIFONI, Enrico (a cura di). Storia Medievale. Roma: Donzelli, 2003. p. 319-362.

CRONE, Patricia. Pre-Industrial Societies. Oxford: Oneworld, 2003.

CURCIO, Anna. M. Saper Stare in Società: Appunti di Sociologia. Milano: Franco Angeli, 2005 .

DETWILER, Donald S. Germany: A Short History. Carbondale: Southern Illinois University, 1999.

DUBY, Georges. Les féodaux, 980-1075 In: DUBY, Georges. (Dir.). Histoire de la France. Paris: Larousse, 1999. p. 203-228.

FLORI, Jean La Chevalerie. Paris: Gisserot, 1998.

GRAVETT, Christopher. German Medieval Armies 1000-1300. London: Osprey, 1997.

GROTEN, M. Forms of economic life in the High Middle Ages In: TOMAN, Rolf. (Ed.). The High Middle Ages in Germany. Köln: Benedikt Taschen, 1990. p. 66-85.

HANSEN, Susan; RAPLEY, Mark. Group(s) In: TURNER, Bryan. (Ed.). The Cambridge Dictionary of Sociology. New York: Cambridge University Press, 2006.

HOLY, L. Groups In: KUPER, Adam; KUPER, Jessica (Eds.) The Social Science Encyclopedia. London/New York: Routledge, 2003. p. 602-603.

LE BAS, Ph. France: Dictionnaire Encyclopédique. Paris: Firmin Didot, 1842. Tome septième.

LINDSAY, James. E. Daily Life in the Medieval Islamic World. Indianapolis/Cambridge: Hackett, 2005.

LOHSE, Tilmann. Ways of life in the estates of society in the Middle Ages. In: TOMAN, Rolf. (Ed.) The High Middle Ages in Germany. Köln: Benedikt Taschen, 1990. p. 8-39.

MARCHANT, J. Cassells Latin Dictionary. London: Cassell and Company, 1904.

MARTÍN, J.L. La España Medieval. Madrid: Historia 16 (Manual de História de España), 1993. Tomo II.

MUSTAFA, Sam A. Germany in the Modern World: A New History. Lanham, Maryland: Rowman \& Littlefield, 2011.

PARISSE, M. Ministériaux In: VAUCHEZ, André. (Dir.). Dictionnaire Encyclopédique du Moyen Âge. Paris/Rome/Cambridge: Ed. du Cerf/Cittá Nuova/James Clarke \& Co., 1997. Tome II, p. 1004-1005. 
PEDANI, Maria Pia. Breve Storia dell Impero Ottomano. Roma: Aracne, 2006.

PIXTON, Paul Brewer. Ministerials In: JEEP, John M. (Ed.). Medieval Germany: An Encyclopedia. London: Routledge, 2001. p. 523-524.

ROSENWEIN, Barbara H. A Short History of the Middle Ages. Toronto: University of Toronto Press, 2009.

SINGMAN, Jeffrey. L. Daily Life in Medieval Europe. Westport: Greenwood, 1999.

STRAYER, Joseph R. Feudalism. Princeton: Van Nostrand, 1965.

TOSCANO, Mario A. Introduzione alla Sociologia. Milano: Franco Angeli, 2006.

TURK, Eleanor L. The History of Germany. Westport/London: Greenwood, 1999.

VALDEAVELLANO Y ARCIMIS, Luis García de. Sobre los Burgos y los Burgueses de la España Medieval. Madrid: Real Academia de Historia, 1960.

Submissão em: 14/01/2013

Revisão em: 23/04/2013

Aceite em: 08/06/2013

José Henrique Rollo Gonçalves é Doutor em História Comparada pela UFRJ (2013); professor dos Cursos de História e de Comunicação e Multimeios da Universidade Estadual de Maringá - UEM. Endereço: Avenida Colombo, 5790. Jardim Universitário, Maringá/PR, Brasil. CEP 87020-900 E-mail: jhrollogoncalves@,hotmail.com 